\title{
A Phase II, Randomized, Double-Blind, Placebo- Controlled, Dose-Ranging Study of Belimumab in Patients With Active Systemic Lupus Erythematosus
}

\author{
DANIEL J. WALLACE, ${ }^{1}$ WILLIAM STOHL, ${ }^{2}$ RICHARD A. FURIE, ${ }^{3}$ JEFFREY R. LISSE, ${ }^{4}$ \\ JAMES D. MCKAY, ${ }^{5}$ JOAN T. MERRILL, ${ }^{6}$ MICHELLE A. PETRI, ${ }^{7}$ ELLEN M. GINZLER, ${ }^{8}$ \\ W. WINN CHATHAM, ${ }^{9}$ W. JOSEPH MCCUNE, ${ }^{10}$ VIVIAN FERNANDEZ, ${ }^{11}$ MARC R. CHEVRIER, ${ }^{11}$ \\ Z. JOHN ZHONG, ${ }^{11}$ AND WILLIAM W. FREIMUTH ${ }^{11}$
}

Objective. To assess the safety, tolerability, biologic activity, and efficacy of belimumab in combination with standard of care therapy (SOC) in patients with active systemic lupus erythematosus (SLE).

Methods. Patients with a Safety of Estrogens in Lupus Erythematosus: National Assessment (SELENA) version of the Systemic Lupus Erythematosus Disease Activity Index (SLEDAI) score $\geq 4(n=449)$ were randomly assigned to belimumab $(1,4$, or $10 \mathrm{mg} / \mathrm{kg})$ or placebo in a 52-week study. Coprimary end points were the percent change in the SELENA-SLEDAI score at week 24 and the time to first SLE flare.

Results. Significant differences between the treatment and placebo groups were not attained for either primary end point, and no dose response was observed. Reductions in SELENA-SLEDAI scores from baseline were $19.5 \%$ in the combined belimumab group versus $17.2 \%$ in the placebo group. The median time to first SLE flare was 67 days in the combined belimumab group versus 83 days in the placebo group. However, the median time to first SLE flare during weeks $24-52$ was significantly longer with belimumab treatment (154 versus 108 days; $P=0.0361)$. In the subgroup (71.5\%) of serologically active patients (antinuclear antibody titer $\geq 1: 80$ and/or anti-double-stranded DNA [anti-dsDNA] $\geq 30$ $\mathrm{IU} / \mathrm{ml}$ ), belimumab treatment resulted in significantly better responses at week 52 than placebo for SELENA-SLEDAI score $(-28.8 \%$ versus $-14.2 \% ; P=0.0435)$, physician's global assessment $(-32.7 \%$ versus $-10.7 \% ; P=0.0011)$, and Short Form 36 physical component score $(+3.0$ versus +1.2 points; $P=0.0410)$. Treatment with belimumab resulted in a $63-71 \%$ reduction of naive, activated, and plasmacytoid CD20+ $\mathrm{B}$ cells, and a $29.4 \%$ reduction in anti-dsDNA titers $(P=0.0017)$ by week 52. The rates of adverse events and serious adverse events were similar in the belimumab and placebo groups.

Conclusion. Belimumab was biologically active and well tolerated. The effect of belimumab on the reduction of SLE disease activity or flares was not significant. However, serologically active SLE patients responded significantly better to belimumab therapy plus SOC than to SOC alone.

\section{INTRODUCTION}

B lymphocyte stimulator (BLyS; trademark of Human Genome Sciences, Rockville, MD), a 285-amino acid protein member of the tumor necrosis factor ligand superfamily, is

ClinicalTrials.gov identifier: NCT00071487.

The General Clinical Research Center at the University of Southern California Keck School of Medicine, Los Angeles, California, is supported in part by the NIH (grant M01RR00043).

${ }^{1}$ Daniel J. Wallace, MD, FACP, FACR: Cedars-Sinai Medical Center, University of California, Los Angeles; ${ }^{2}$ William Stohl, MD, PhD: University of Southern California Keck School of Medicine and Los Angeles County-University of Southern California Medical Center, Los Angeles; ${ }^{3}$ Richard A. Furie, MD: North Shore-Long Island Jewish Health System, Lake Success, New York; ${ }^{4}$ Jeffrey R. Lisse, MD: The University of Arizona Arthritis Center, Tucson; ${ }^{5}$ James D. a key B cell survival factor (1) and binds 3 membrane receptors (TACI, BCMA, and BAFF-R/B lymphocyte stimulator receptor 3 [BR-3]) on B lymphocytes (2-4). BLyS inhibits B cell apoptosis and stimulates the differentiation of B cells into immunoglobulin-producing plasma cells

McKay, DO: Oklahoma Center for Arthritis Therapy and Research, Tulsa; ${ }^{6}$ Joan T. Merrill, MD: Oklahoma Medical Research Center, Oklahoma City; ${ }^{7}$ Michelle A. Petri, MD, MPH: Johns Hopkins University, Baltimore, Maryland; ${ }^{8}$ Ellen M. Ginzler, MD, MPH: State University of New York Downstate Medical Center, Brooklyn; ${ }^{9} \mathrm{~W}$. Winn Chatham, MD: University of Alabama, Birmingham; ${ }^{10} \mathrm{~W}$. Joseph McCune, MD: University of Michigan Medical Center, Ann Arbor; ${ }^{11}$ Vivian Fernandez, BS, Marc R. Chevrier, MD, PhD, FACR (current address: Centocor, Inc., Horsham, Pennsylvania), Z. John Zhong, PhD, William W. Freimuth, MD, PhD: Human Genome Sciences, Inc., Rockville, Maryland. 
(5). Constitutive overexpression of BLyS by mice that harbor a blys transgene results in a systemic lupus erythematosus (SLE)-like autoimmune-like disease (6-8). Conversely, genetic disruption of the blys gene in SLE-prone NZM 2328 mice markedly attenuates the development of clinical disease (9). Moreover, soluble BLyS receptors (TACI-Fc or BR-3-Fc) administered to SLE-prone (NZB $\times$ $\mathrm{NZW}) \mathrm{F}_{1}$ or MRL-lpr/lpr mice slowed disease progression and improved survival $(2,10)$.

BLyS is overexpressed in patients with SLE and other autoimmune diseases (11-14). BLyS levels and messenger RNA expression correlate with changes in SLE disease activity and anti-double-stranded DNA (anti-dsDNA) antibody titers $(11,14-16)$.

Belimumab is a fully human IgG1 $\lambda$ monoclonal antibody that binds to soluble human BLyS and inhibits its biologic activity $(17,18)$. In a phase I dose-escalation study performed in 70 patients with SLE, no related serious adverse events (AEs) or safety signals were reported, and evidence of biologic activity included reductions in CD20+ B cells and anti-dsDNA antibody titers (19). A phase II doseranging trial of belimumab was designed to evaluate the safety, efficacy, and biologic activity of belimumab in SLE patients with active disease who were receiving standard of care therapy (SOC). Secondary and exploratory analyses were performed to better understand the effects of belimumab and to identify the ideal study population for phase III studies.

\section{PATIENTS AND METHODS}

Study design. Patients were randomized to receive 1,4 , or $10 \mathrm{mg} / \mathrm{kg}$ of belimumab or placebo by intravenous infusion over 2 hours on days 0,14 , and 28 , and then every 28 days for 52 weeks plus SOC. Hematology, chemistry,

Dr. Stohl has received consultant fees, speaking fees, and/or honoraria (less than \$10,000) from Human Genome Sciences. Dr. Furie has received consultant fees, speaking fees, and/or honoraria (less than $\$ \mathbf{1 0 , 0 0 0}$ ) from Human Genome Sciences. Dr. McKay owns stock and/or holds stock options in Human Genome Sciences. Dr. Merrill has received consultant fees, speaking fees, and/or honoraria (less than $\$ 10,000)$ from Human Genome Sciences, and has served as a paid investment analyst consultant. Dr. Petri has received consultant fees, speaking fees, and/or honoraria (less than \$10,000) from Human Genome Sciences, and has served as a paid investment analyst consultant. Dr. Ginzler has received consultant fees, speaking fees, and/or honoraria (less than \$10,000) from Human Genome Sciences, and has served as a paid investment consultant for Guidepoint Global and Gerson Lehrman Group. Dr. McCune has received consultant fees, speaking fees, and/or honoraria (less than $\$ 10,000$ each) from Genentech and Johnson \& Johnson/ Centocor. Ms Fernandez and Drs. Zhong and Freimuth own stock and/or hold stock options in Human Genome Sciences. Dr. Chevrier holds a patent for the definition of systemic lupus erythematosus serologic activity.

Address correspondence to Daniel J. Wallace, MD, FACP, FACR, 8737 Beverly Boulevard, Suite 302, West Hollywood, CA 90048. E-mail: dwallace@ucla.edu.

Submitted for publication October 21, 2008; accepted in revised form May 12, 2009. urinalysis, 24-hour urine collection, biologic markers, autoantibodies, SLE disease activity scales (the Safety of Estrogens in Lupus Erythematosus: National Assessment [SELENA] version of the Systemic Lupus Erythematosus Disease Activity Index [SLEDAI] [20], the SELENASLEDAI flare index [SFI] [21], and the British Isles Lupus Assessment Group [BILAG] instrument [22,23]), physician's global assessment (PGA), and the Short Form 36 health survey (SF-36) (24) were evaluated every 4 weeks during the first 24 weeks, and then at weeks $32,40,48$, and 52. Changes to immunosuppressive agents and corticosteroid therapy were permitted as clinically indicated.

Entry criteria. Adult patients (age $\geq 18$ years) fulfilling the American College of Rheumatology (ACR) criteria for SLE who had active disease as defined by a SELENASLEDAI score of $\geq 4$ at screening were eligible for enrollment (25). Inclusion criteria mandated a history of measurable autoantibodies (including any of the following: antinuclear antibodies [ANAs], anti-dsDNA, anti-Sm, antiRNP, anti-Ro, anti-La, or anticardiolipin), but they did not have to be present at screening. In addition, adult patients were required to be receiving a stable regimen of prednisone (5-40 mg/day), antimalarials, or immunosuppressive agents for at least 60 days prior to day 0 (first dose). Key exclusion criteria included active lupus nephritis or central nervous system disease, pregnancy, and receipt of cyclosporine, intravenous immunoglobulin, biologics, cyclophosphamide, or dosages of prednisone $>100 \mathrm{mg}$ /day within 6 months. Patients were stratified according to their screening SELENA-SLEDAI scores $(4-7$ versus $\geq 8$ ).

Efficacy measures. The coprimary efficacy end points were the percent change in the SELENA-SLEDAI score from baseline (day 0) to week 24 and the time to first $\mathrm{mild} /$ moderate or severe flare as defined by the SFI (21) during 52 weeks. Secondary efficacy end points included changes in week 52 SELENA-SLEDAI and BILAG scores, time to first SLE flare (assessed by the SFI or BILAG) during and after the first 24 weeks, and the percentage of patients with a prednisone dosage $\leq 7.5 \mathrm{mg} /$ day or reduced by $50 \%$ from baseline during weeks $40-52$. Other secondary efficacy end points evaluating change from baseline over 52 weeks included autoantibody and complement levels, corticosteroid doses, B cell and plasma cell subsets, PGA, SF-36, impact on organ-specific disease, and immunoglobulin levels. Exploratory analyses were performed to identify subgroups with superior treatment responses.

Biologic markers, autoantibodies, and B cell populations. Anti-dsDNA antibody, ANA, IgG, IgM, IgE, IgA, and complement (C3 and C4) levels were measured every 1 to 2 months. Serum BLyS levels were determined only at day 0 (prior to belimumab dosing) because belimumab interferes with accurate measurements of BLyS (26). ANAs were determined by a screening enzyme-linked immunosorbent assay, and all positive samples underwent immunofluorescence testing on HEp-2 cells (Quest Laboratories, Van Nuys, CA). Peripheral blood lymphocytes, collected every 1 to 2 months, were forwarded to a central fluorescence-activated cell sorting facility (Nichols Labo- 
ratory, La Jolla, CA). Cells were stained with combinations of antibodies to identify multiple $\mathrm{B}$ cell subsets (naive [CD20+/CD27-], memory [CD20+/CD27+], activated [CD20+/CD69+], and plasmacytoid [CD20+/CD138+]) and plasma cells (CD20-/CD138+ and CD20-/CD27 $\left.{ }^{\text {high }}\right)$, as well as a specific SLE subset (CD19+/CD38 $8^{\text {bright/ }}$ CD27 ${ }^{\text {bright }}$ ) of plasma cells (27).

Statistical methods. Differences in SELENA-SLEDAI scores at week 24 between groups were analyzed using a 2-sample $t$-test, and the time to first flare over 52 weeks was evaluated with the log rank test. Missing data in SELENA-SLEDAI were imputed using a last observation carried forward method. The analysis of primary efficacy end points was performed in a modified intent-to-treat population, defined as all patients who were randomized and received a dose of the study agent. Discrete variables were analyzed using a likelihood chi-square test and continuous variables were analyzed using the Student's $t$-test or the Wilcoxon's rank sum test, as appropriate.

The sample size was based on the 2 coprimary efficacy end points. The study was designed to have at least $80 \%$ power at a $2.5 \%$ significance level to detect in one of the active groups: 1) a $25 \%$ absolute or $100 \%$ relative improvement in the percent change from baseline score in the SELENA-SLEDAI (assuming an average decrease of $25 \%$ from baseline in the placebo group with an SD of $50 \%$ ) at week 24, and 2) a reduction in the percentage of patients having their first SLE flare by week 52 from $65 \%$ in the placebo group to $43 \%$ in any of the belimumab treatment groups.

Informed consent. All patients gave written informed consent, which was approved by either a central or local institutional review board. An independent data monitoring committee reviewed safety data approximately every 3 months.

\section{RESULTS}

Patient disposition and demographics. Belimumab was administered to 336 patients and placebo was administered to 113 patients at 59 sites in the US and Canada from October 2003 to August 2005 (Figure 1). There were no

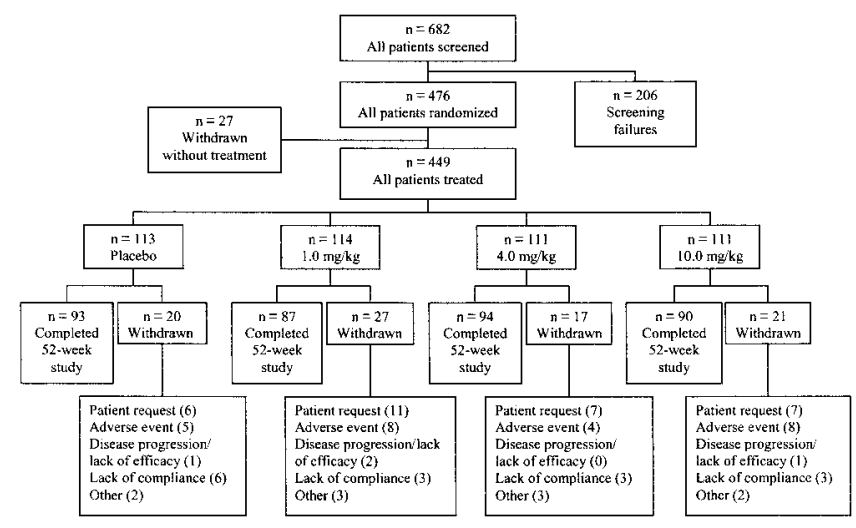

Figure 1. Flow diagram of patient disposition during the study. significant differences among treatment groups in baseline features (Table 1) or in reasons for discontinuation (Figure 1).

Primary clinical end points. Changes in SELENASLEDAI scores. There were no significant differences between any of the individual belimumab treatment groups and the placebo group with regard to the percent changes in the SELENA-SLEDAI scores from baseline to weeks 24 or 52. Mean percent changes in SELENA-SLEDAI scores were $-19.5 \%$ for the combined belimumab groups versus $-17.2 \%$ for the placebo group at 24 weeks, and $-27.2 \%$ for the belimumab-treated groups versus $-20.6 \%$ for the placebo group at 52 weeks (Table 2). Dose-dependent effects on changes in the SELENA-SLEDAI score were not observed. The modification of the SELENA-SLEDAI score by excluding contributions of anti-dsDNA and/or low complement did not reduce the treatment effect of belimumab (Table 2).

Flare rates. Based on the SFI, $59 \%, 78 \%$, and $87 \%$ of all patients (including placebo) experienced an SLE flare (mild/moderate or severe) by weeks 12, 24, and 52, respectively, and there were no dose-dependent differences among the 4 treatment groups (Figure 2A). Severe flares were reported in $32 \%$ of both belimumab and placebo groups over 52 weeks. Excluding severe flares triggered solely by SELENA-SLEDAI score changes to $>12$ without clinical manifestations, the severe flare rates were $20.4 \%$ in the placebo group and $15.2 \%$ in the belimumab group ( $P$ $=0.2080$ ).

Time to first flare. There was no significant difference in the time to first SFI-defined flare over 52 weeks between the combined belimumab and placebo groups (67 versus 83 days) (Table 2). However, an analysis of time to first flare starting at week 24 through week 52 (Figure 2B and Table 2) revealed a median time to flare of 154 days in the belimumab group and 108 days in the placebo group $(P=$ 0.0361), suggesting that belimumab can stabilize disease, but requires some time to do so. During the second half of the study (weeks 24-52), severe flares were observed in $12 \%$ of belimumab-treated patients and in $17 \%$ of placebotreated patients $(P=0.1807)$.

Secondary and exploratory clinical end points in all patients. Corticosteroid dose and immunosuppressive agents. Among patients whose baseline prednisone dosage was $>7.5 \mathrm{mg} /$ day, $44.7 \%$ of patients receiving 10 $\mathrm{mg} / \mathrm{kg}$ of belimumab were able to reduce their steroid dosage by $50 \%$ or to $\leq 7.5 \mathrm{mg} /$ day in the last 3 months prior to the week 52 visit (versus $27.1 \%$ in the placebo group; $P=0.0882$ ). The prednisone dosage during the last 2 months of the study was reduced by an average of 3.1 $\mathrm{mg} /$ day $(-19.9 \%)$ in the combined belimumab group versus $1.9 \mathrm{mg} /$ day $(-11.7 \%)$ in the placebo group, with the treatment group receiving $10 \mathrm{mg} / \mathrm{kg}$ of belimumab having the best response $(6.4 \mathrm{mg} /$ day $[-40.5 \%] ; P=0.2218)$. In patients receiving either no steroids or low-dose steroids ( $\leq 7.5 \mathrm{mg} /$ day) at baseline, $2.7 \%$ of the patients treated with $10 \mathrm{mg} / \mathrm{kg}$ of belimumab (compared with $12.3 \%$ of placebo patients; $P=0.0459$ ) (Table 2) had their average prednisone dosage increased to $>7.5 \mathrm{mg} /$ day. Over 52 


\begin{tabular}{|c|c|c|c|c|c|}
\hline & \multirow[b]{2}{*}{$\begin{array}{l}\text { Placebo } \\
(n=113)\end{array}$} & \multicolumn{4}{|c|}{ Belimumab } \\
\hline & & $\begin{array}{l}1.0 \mathrm{mg} / \mathrm{kg} \\
(\mathrm{n}=114)\end{array}$ & $\begin{array}{l}4.0 \mathrm{mg} / \mathrm{kg} \\
(\mathrm{n}=111)\end{array}$ & $\begin{array}{l}10.0 \mathrm{mg} / \mathrm{kg} \\
(\mathrm{n}=111)\end{array}$ & $\begin{array}{l}\text { All active } \\
(n=336)\end{array}$ \\
\hline Women & 90.3 & 93.9 & 94.6 & 94.6 & 94.3 \\
\hline \multicolumn{6}{|l|}{ Race } \\
\hline White & 70.8 & 71.9 & 67.6 & 70.3 & 69.9 \\
\hline African American & 20.4 & 21.1 & 27.9 & 25.2 & 24.7 \\
\hline Hispanic or Latino origin & 18.6 & 14.9 & 21.6 & 18.9 & 18.5 \\
\hline Age, mean \pm SD years & $42.2 \pm 10.9$ & $42.0 \pm 11.7$ & $42.6 \pm 10.7$ & $41.8 \pm 11.7$ & $42.1 \pm 11.3$ \\
\hline Disease duration, mean \pm SD years & $8.1 \pm 7.4$ & $8.5 \pm 7.2$ & $10.1 \pm 9.2$ & $8.5 \pm 8.0$ & $9.0 \pm 8.2$ \\
\hline SELENA-SLEDAI score, mean \pm SEM & $9.5 \pm 0.5$ & $9.9 \pm 0.4$ & $9.4 \pm 0.5$ & $9.5 \pm 0.4$ & $9.6 \pm 0.3$ \\
\hline$\geq 1$ BILAG A or B score & 90.3 & 95.6 & 96.4 & 97.5 & 95.8 \\
\hline PGA, mean \pm SEM & $1.4 \pm 0.05$ & $1.6 \pm 0.05$ & $1.5 \pm 0.05$ & $1.5 \pm 0.05$ & $1.5 \pm 0.03$ \\
\hline Daily prednisone use & 72.6 & 68.4 & 65.8 & 66.7 & 67.0 \\
\hline$>7.5 \mathrm{mg} /$ day at baseline & 42.5 & 35.1 & 31.5 & 34.2 & 33.6 \\
\hline Immunosuppressive agent uset & 48.7 & 45.6 & 53.2 & 52.3 & 50.3 \\
\hline Antimalarial use & 74.3 & 70.2 & 64.9 & 69.4 & 68.2 \\
\hline BLyS ALOD & 43.4 & 43.0 & 44.1 & 43.2 & 43.5 \\
\hline ANA titer $\geq 1: 80$ & 74.3 & 70.2 & 73.9 & 66.7 & 70.2 \\
\hline Anti-dsDNA $\geq 30 \mathrm{IU} / \mathrm{ml}$ & 51.3 & 51.8 & 47.7 & 47.7 & 49.1 \\
\hline Serologically active $\neq$ & 76.1 & 68.4 & 71.2 & 70.3 & 69.9 \\
\hline $\mathrm{C} 3$, mean \pm SEM mg/dl & $114.6 \pm 3.4$ & $110.0 \pm 3.6$ & $109.4 \pm 3.0$ & $112.7 \pm 3.5$ & $110.7 \pm 2.0$ \\
\hline C4, mean \pm SEM mg/dl & $20.2 \pm 1.0$ & $18.3 \pm 1.0$ & $18.3 \pm 0.9$ & $19.8 \pm 1.0$ & $18.8 \pm 0.6$ \\
\hline $\mathrm{IgG}$, mean $\pm \mathrm{SEM} \mathrm{mg} / \mathrm{dl}$ & $1,366.8 \pm 55.1$ & $1,372.7 \pm 48.4$ & $1,385.4 \pm 48.8$ & $1,407.3 \pm 54.3$ & $1,388.3 \pm 29.1$ \\
\hline $\mathrm{IgA}$, mean $\pm \mathrm{SEM}$ mg/dl & $300.8 \pm 18.6$ & $285.2 \pm 15.4$ & $278.2 \pm 15.3$ & $303.8 \pm 14.9$ & $289.0 \pm 8.8$ \\
\hline IgM, mean \pm SEM mg/dl & $101.5 \pm 6.9$ & $117.7 \pm 8.1$ & $127.6 \pm 9.7$ & $103.2 \pm 7.1$ & $116.2 \pm 4.9$ \\
\hline IgE, mean \pm SEM KU/liter & $70.8 \pm 13.4$ & $114.1 \pm 22.9$ & $127.7 \pm 31.9$ & $91.4 \pm 18.4$ & $111.1 \pm 14.4$ \\
\hline \multicolumn{6}{|l|}{$\begin{array}{l}\text { History of SLE disease manifestations } \\
\text { (per ACR criteria) }\end{array}$} \\
\hline Arthritis & 92.9 & 95.6 & 91.9 & 93.7 & 93.8 \\
\hline Renal disorder & 22.1 & 35.1 & 25.2 & 35.1 & 31.8 \\
\hline Neurologic disorder & 8.0 & 9.6 & 12.6 & 7.2 & 9.8 \\
\hline Hematologic disorder & 44.2 & 54.4 & 49.5 & 58.6 & 54.2 \\
\hline Immunologic disorder & 71.7 & 74.6 & 72.1 & 72.1 & 72.9 \\
\hline ANA & 98.2 & 96.5 & 99.1 & 96.4 & 97.3 \\
\hline \multicolumn{6}{|c|}{$\begin{array}{l}\text { * Values are the percentage unless otherwise indicated. SELENA-SLEDAI = Safety of Estrogens in Lupus Erythematosus: National Assessment version } \\
\text { of the Systemic Lupus Erythematosus Disease Activity Index; BILAG = British Isles Lupus Assessment Group; PGA = physician's global assessment; } \\
\text { BLyS = B lymphocyte stimulator; ALOD = above limit of detection }(0.350 \mathrm{ng} / \mathrm{ml}) \text {; ANA = antinuclear antibody; anti-dsDNA = anti-double-stranded } \\
\text { DNA; KU = Kunitz units; SLE = systemic lupus erythematosus; ACR = American College of Rheumatology. } \\
\text { t Excluding aminoquinoline antimalarials (hydroxychloroquine, chloroquine, and quinacrine). } \\
\text { ‡ ANA titer } \geq 1: 80 \text { and/or anti-dsDNA positive at screening and day } 0 \text {. }\end{array}$} \\
\hline
\end{tabular}

weeks of therapy, a new immunosuppressive agent was added to $6.2 \%$ of patients in the combined belimumab group versus $11.5 \%$ of the placebo group $(P=0.0799)$, and no significant differences were observed in discontinuing an immunosuppressive agent.

PGA and SF-36 physical component summary (PCS) score. Significant mean changes in PGA (21) in the combined belimumab group were observed as early as week 4 , and by 52 weeks there was a $31 \%$ decrease in mean PGA score in the combined belimumab group compared with a $14 \%$ decrease in the placebo group $(P=0.0019)$ (Table 2$)$. Similarly, there was a trend toward improvement in the SF-36 PCS (24) at week 52 in the combined belimumab group $(+2.6$ points versus +1.4 points in the placebo group; $P=0.0979$ ). Significant increases of 3.4 points in the PCS at week 52 in patients receiving a $10 \mathrm{mg} / \mathrm{kg}$ dose of belimumab were observed $(P=0.0167)$ (Table 2). An increase of $\geq 2.5$ points from baseline in the PCS is con- sidered to be the minimum clinically important difference (28).

BILAG. The incidence of new A or B organ system domain flares in the combined belimumab group was similar to that in the placebo group at week $52(29.5 \%$ versus $35.4 \% ; P=0.2416$ ) (Table 2). Moreover, there were no significant improvements in mean BILAG composite scores or individual organ domain scores in belimumabtreated groups compared with placebo (results not shown).

Exploratory subgroup analyses of SELENA-SLEDAI responses. Statistically significant percent changes in SELENA-SLEDAI scores from baseline to week 52 were associated with belimumab treatment compared with placebo treatment in patients with the following baseline characteristics: anti-dsDNA antibody positivity, low C3, low C4, prednisone dosage $>7.5 \mathrm{mg} /$ day, and serologic activity (ANA titer $\geq 1: 80$ or anti-dsDNA antibodies $>30$ $\mathrm{IU} / \mathrm{ml}$ ) at both screening and day 0 (Figure 2C). Baseline 


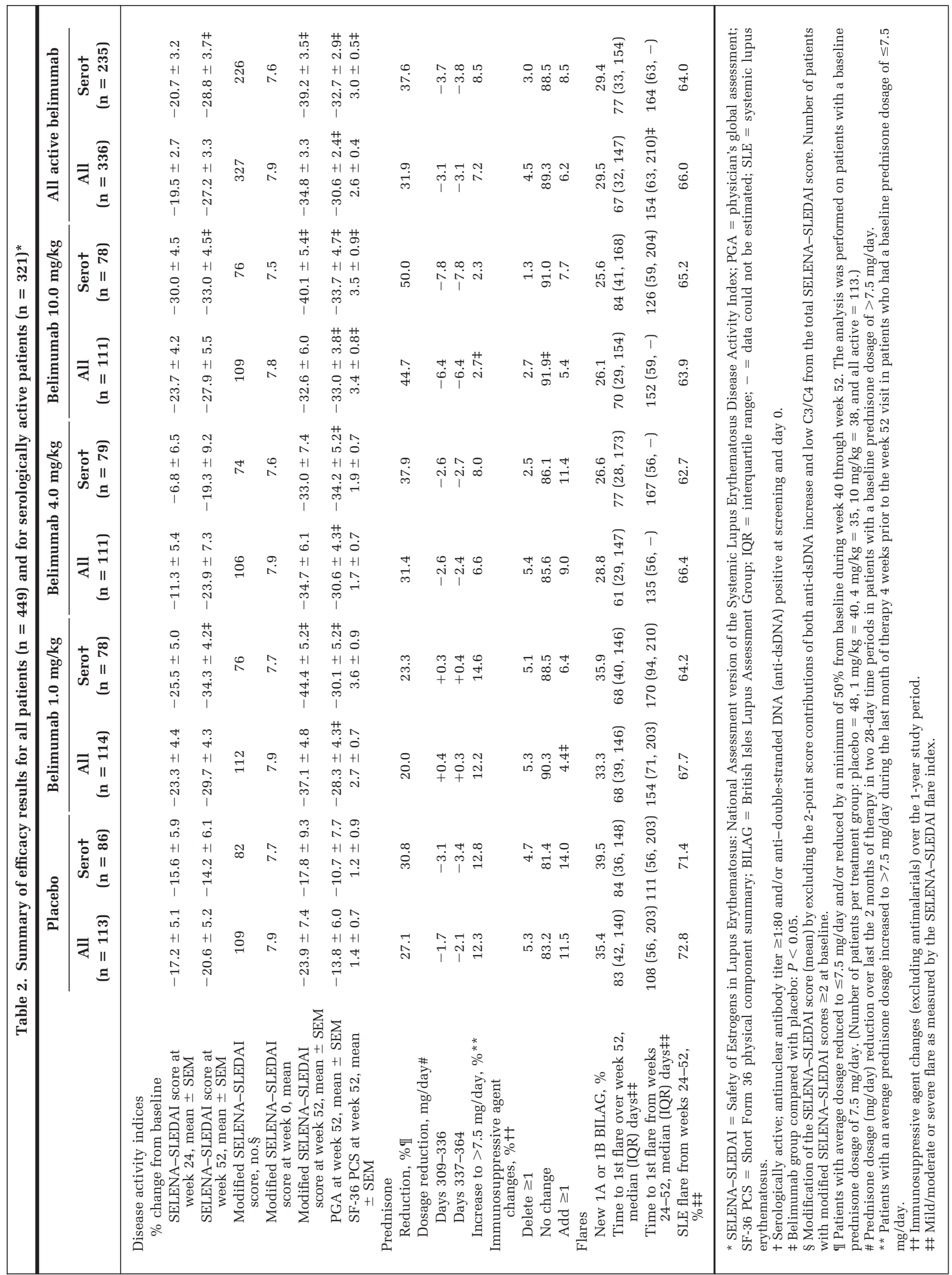




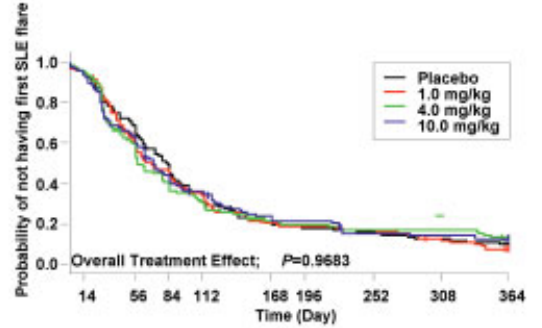

A

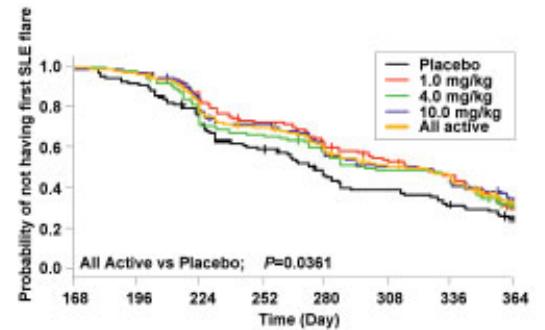

B

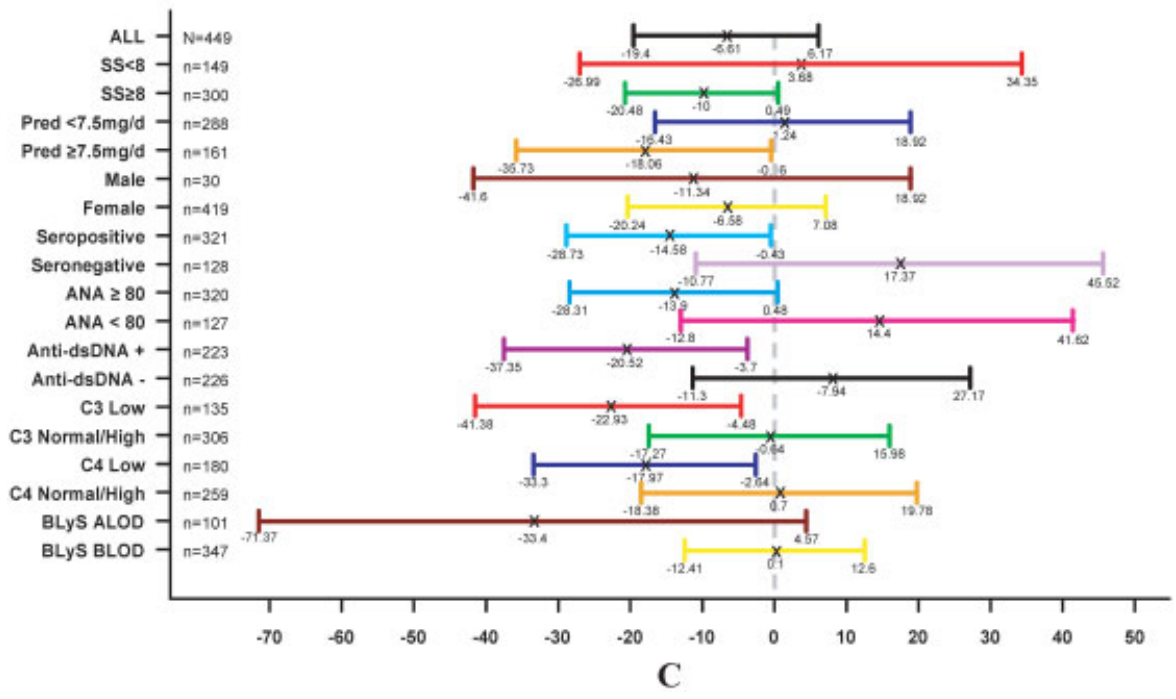

Figure 2. Time to first mild/moderate or severe flare as measured by the Safety of Estrogens in Lupus Erythematosus: National Assessment version of the Systemic Lupus Erythematosus Disease Activity Index (SS) flare index and subgroup analysis of response to the 52-week SS score. A, Time to first systemic lupus erythematosus (SLE) flare for all treated patients from weeks 0 to 52 ( $\log$ rank test for overall treatment effect: $P=0.9683$ ). B, Time from day 168 to the first SLE flare that occurred after day 168 for all patients (log rank test for combined belimumab vs. placebo: $P=0.0361$ ). C, Mean percent change from baseline in SS score at week 52 in different subgroups (belimumab vs. placebo). Each subgroup analyzed the response rate between the groups treated with belimumab and the placebo group, where the absolute percent difference from placebo is set at 0 and the $95 \%$ confidence interval values are shown. Pred = prednisone; ANA = antinuclear antibody; anti-dsDNA = anti-doublestranded DNA; BLyS = B lymphocyte stimulator; ALOD = above limit of detection $(0.350$ $\mathrm{ng} / \mathrm{ml}$ ); BLOD = below limit of detection.

characteristics associated with favorable trends in SELENA-SLEDAI scores (a mean difference between belimumab treatment and placebo of a $\geq 10 \%$ reduction, but not statistically significant) were SELENA-SLEDAI scores $\geq 8$, an ANA titer of $\geq 1: 80$ at both screening and day 0 , and elevated BLyS levels at day 0.

Biologic activity. $B$ cell subsets. There was no significant dose response observed in modulation of B cell subsets (Figure 3), plasma cell subsets (data not shown), or with any of the other biomarkers examined (C3, C4, antidsDNA antibody, ANA, or immunoglobulin isotypes) in the belimumab groups over 52 weeks (data not shown). Therefore, all belimumab treatment groups were combined for analyses of biomarker data. Continuous treatment with belimumab led to significant median percent reductions by week 24 of $30-59 \%(P<0.0001)$ in selected B cell counts $/ \mathrm{mm}^{3}$, and by week 52 , the percent changes were $-49.3 \%$ for CD19+, $-54.1 \%$ for CD20+, $-70.8 \%$ for naive
B cells, $-70.4 \%$ for activated B cells, and $-62.5 \%$ for plasmacytoid B cells. Conversely, in the combined belimumab group, the percent change in the median value of memory B cells was increased by $88 \%$ by day $28(P<$ 0.0001 ), and gradually returned to baseline by week 52 (Figure 3D). The percent changes from baseline in the SLE subset of plasma cells at week 52 were significantly different between the belimumab treatment group and the placebo group $(-18.2 \%$ versus $+28.6 \% ; P=0.0027)$. No significant group differences were noted in the changes in plasma cells between the belimumab and placebo groups.

Immunoglobulin concentrations. Median serum concentrations of IgG, IgA, IgM, and IgE decreased by $10 \%$, $14 \%, 29 \%$, and $34 \%$, respectively, at week 52 in the belimumab-treated group $(P<0.0001$ for all immunoglobulin isotypes) compared with a $<5 \%$ change from baseline for the placebo group (data not shown). Reductions were observed as early as week 8 in all immunoglobulin isotypes. There was a significantly greater number of patients re- 


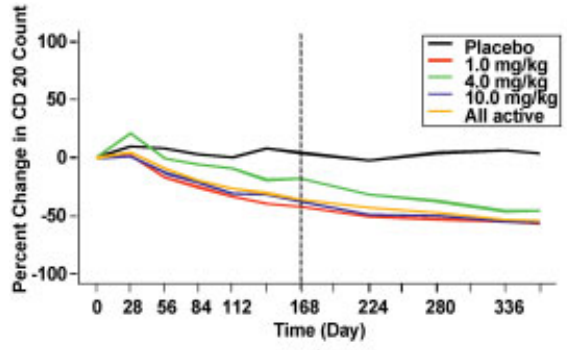

A

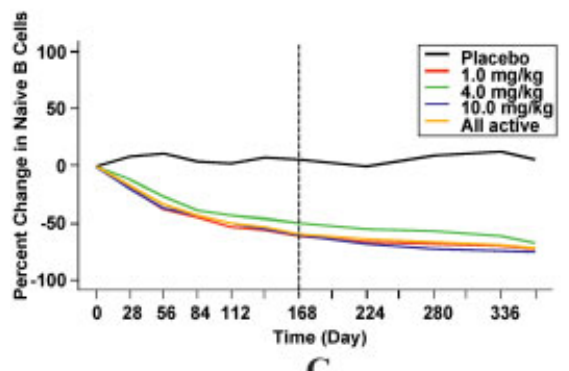

C

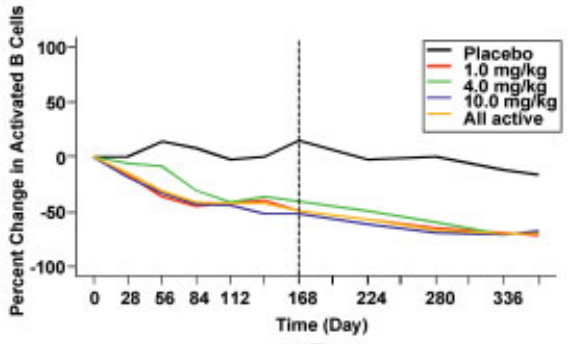

B

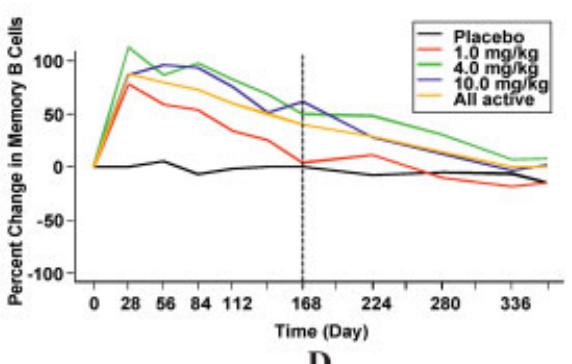

D

Figure 3. Median percent change in B cell subsets over 1 year of belimumab therapy or placebo added to standard of care therapy in A, CD20+ B cells, B, activated (CD20+/CD27-) B cells, C, naive (CD20+/CD69+) B cells, and D, memory (CD20+/CD27+) B cells. The baseline B cell values in all 4 treatment groups were not significantly different. B cell values are shown in absolute numbers for all patients combined: CD19 $=163.6 / \mathrm{mm}^{3}$, CD20 $=$ $157.3 / \mathrm{mm}^{3}$, naive $=120.4 / \mathrm{mm}^{3}$, activated $=25.1 / \mathrm{mm}^{3}$, memory $=36.6 / \mathrm{mm}^{3}$, plasmacytoid $=6.6 / \mathrm{mm}^{3}$ (not shown), and plasma cells $=3.9 / \mathrm{mm}^{3}$ (not shown). B cell subsets were unaffected in the placebo group by week 52 except for plasmacytoid cells, which declined by $33 \%$ (data not shown).

ceiving belimumab $(31.4 \%$ versus $19.4 \%$ receiving placebo; $P<0.0192$ ) who had low IgM at week 52, but not IgG or IgA (Table 3).

ANAs and complement levels. IgG anti-dsDNA antibodies decreased early in the study. In patients with IgG anti-dsDNA antibodies at baseline, median reductions of $29.4 \%$ and $8.6 \%$ were observed in the combined belimumab and placebo groups, respectively $(P=0.0017)$. Anti-dsDNA antibodies became negative in $14.6 \%$ of belimumab-treated patients versus $3.4 \%$ of placebo-treated patients at week $52(P=0.0119)$. Median changes in $\mathrm{C} 4$ levels in the belimumab group at week 52 were $+22.7 \%$ versus $+7.7 \%$ in the placebo group $(P<0.0001)$ for all treated patients, and $+33.3 \%$ versus $+14.3 \%$ in the placebo group $(P=0.0143)$ in those patients with low $(<16$ $\mathrm{mg} / \mathrm{dl}$ ) baseline C4 concentrations (data not shown). Median percent changes in C3 levels at week 52 were $-2.1 \%$ in the belimumab-treated patients versus $-6.5 \%$ in the placebo group $(P=0.0362)$, and $+6.3 \%$ in patients with low $(<90 \mathrm{mg} / \mathrm{dl}) \mathrm{C} 3$ concentrations at baseline versus $-0.8 \%$ in the placebo group $(P=0.15)$.

Safety and tolerability. During the 52-week study and 8-week followup period, the incidences of AEs by individual event or Medical Dictionary for Regulatory Activities system organ class, serious or severe AEs, and laboratory abnormalities were similar in all treatment groups, including placebo (Table 3). Only urticaria was statistically more frequent in patients treated with belimumab (4\% versus $0 \%$ ). No significant dose-related increase in AEs was ob- served. Serious AEs occurred in 19.5\% of placebo patients compared with $16.1 \%$ of patients in the belimumabtreated groups. The incidence of infections was $72.6 \%$ in the placebo group versus $75.6 \%$ in the belimumab groups (Table 3). Serious infections occurred in $5.1 \%$ of belimumab-treated patients compared with $3.5 \%$ in the placebo group. Although pneumonia and cellulitis were the most common serious infections, no specific type of infection was more prominent in any of the groups (Table 3). Two deaths (1 suicide and 1 respiratory failure in the 1 $\mathrm{mg} / \mathrm{kg}$ and $10 \mathrm{mg} / \mathrm{kg}$ of belimumab groups, respectively) were reported, and neither was considered to be related to the study drug by the investigator. A basal cell carcinoma in a patient given placebo $(0.9 \%)$ and a squamous cell carcinoma in a patient receiving $10 \mathrm{mg} / \mathrm{kg}$ of belimumab $(0.3 \%)$ were reported. One severe infusion reaction consisting of pruritus occurred in a belimumab-treated patient and resulted in discontinuation of the study drug.

Exploratory subgroup analyses in serologically active patients at baseline. There were 321 serologically active patients compared with 128 patients who were seronegative (29). At study entry, patients in the serologically active group were more often African American (27\% versus $16 \% ; P=0.0199)$, fulfilled a greater number of ACR SLE criteria $(P<0.01)$, were younger (age 41 versus 46 years; $P$ $<0.0001$ ), had more major organs involved (e.g., 34\% versus $19 \%$ renal and $59 \%$ versus 33\% hematologic), fewer cutaneous manifestations, higher mean SELENASLEDAI scores (9.8 versus 8.9), greater prednisone use 
Table 3. Number of patients with treatment-emergent AEs $(n=449)^{*}$

\begin{tabular}{|c|c|c|c|c|c|}
\hline & \multirow[b]{2}{*}{$\begin{array}{l}\text { Placebo } \\
(n=113)\end{array}$} & \multicolumn{4}{|c|}{ Belimumab } \\
\hline & & $\begin{array}{l}1.0 \mathrm{mg} / \mathrm{kg} \\
(\mathrm{n}=114)\end{array}$ & $\begin{array}{l}4.0 \mathrm{mg} / \mathrm{kg} \\
(\mathrm{n}=111)\end{array}$ & $\begin{array}{l}10.0 \mathrm{mg} / \mathrm{kg} \\
(\mathrm{n}=111)\end{array}$ & $\begin{array}{l}\text { All active } \\
(\mathrm{n}=336)\end{array}$ \\
\hline$\geq 1 \mathrm{AE}$ & 97.3 & 97.4 & 96.4 & 97.3 & 97.0 \\
\hline$\geq 1$ serious $\mathrm{AE}$ & 19.5 & 18.4 & 13.5 & 16.2 & 16.1 \\
\hline Infections and infestations & $72.6+$ & $74.6 \ddagger$ & $79.3 \S$ & $73.0 \mathbb{1}$ & 75.6 \\
\hline$\geq 1$ serious infection $\mathrm{AE \#}$ & 3.5 & 6.1 & 6.3 & 2.7 & 5.1 \\
\hline$\geq 1$ severe infection AE\# & 2.7 & 7.0 & 5.4 & 3.6 & 5.4 \\
\hline \multicolumn{6}{|l|}{$\begin{array}{l}\text { By MedDRA system organ class }>40 \% \text { in the all-active } \\
\text { group }\end{array}$} \\
\hline Musculoskeletal and connective tissue disorders & 70.8 & 64.9 & 64.0 & 68.5 & 65.8 \\
\hline Skin and subcutaneous tissue disorders & 50.4 & 63.2 & 58.6 & 49.6 & 57.1 \\
\hline Gastrointestinal disorders & 55.8 & 55.3 & 54.1 & 57.7 & 55.7 \\
\hline Nervous system disorders & 46.9 & 43.9 & 51.4 & 54.1 & 49.7 \\
\hline General disorders and administration site conditions & 54.9 & 41.2 & 57.7 & 48.7 & 49.1 \\
\hline Respiratory, thoracic, and mediastinal disorders & 46.0 & 44.7 & 34.2 & 44.1 & 41.1 \\
\hline \multicolumn{6}{|l|}{ Treatment-emergent AEs $\geq 15 \%$ in the all active group } \\
\hline Arthralgia & 37.2 & 36.0 & 33.3 & 36.9 & 35.4 \\
\hline Upper respiratory tract infection & 29.2 & 31.6 & 32.4 & 26.1 & 30.1 \\
\hline Headache & 23.9 & 25.4 & 27.9 & 31.5 & 28.3 \\
\hline Fatigue & 31.0 & 23.7 & 29.7 & 24.3 & 25.9 \\
\hline Nausea & 23.9 & 27.2 & 19.8 & 29.7 & 25.6 \\
\hline Diarrhea & 16.8 & 16.7 & 20.7 & 15.3 & 17.6 \\
\hline Arthritis & 16.8 & 14.0 & 18.9 & 16.2 & 16.4 \\
\hline Urinary tract infection & 15.9 & 14.0 & 17.1 & 18.0 & 16.4 \\
\hline $\begin{array}{l}\text { Laboratory abnormalities }>2 \% \text { in the all active group, no. } \\
\text { White blood cells }\end{array}$ & 112 & 114 & 110 & 111 & 335 \\
\hline Grade 3 & 2.7 & 3.5 & 4.5 & 4.5 & 4.2 \\
\hline \multicolumn{6}{|l|}{ Neutrophils } \\
\hline Grade 3 & 5.4 & 3.5 & 8.2 & 6.3 & 6.0 \\
\hline Grade 4 & - & 0.9 & 0.9 & 0.9 & 0.9 \\
\hline \multicolumn{6}{|l|}{ Hemoglobin } \\
\hline Grade 3 & 3.6 & 4.4 & 3.6 & 0.9 & 3.0 \\
\hline Grade 4 & - & - & 0.9 & - & 0.3 \\
\hline \multicolumn{6}{|l|}{ Prothrombin time ${ }^{* *}$} \\
\hline Grade 3 & 4.5 & 5.3 & 11.8 & 9.0 & 8.7 \\
\hline Grade 4 & 8.0 & 6.2 & 8.2 & 6.3 & 6.9 \\
\hline \multicolumn{6}{|l|}{ 24-hour urinary protein } \\
\hline Grade 3 & 5.4 & 5.3 & 4.6 & 6.4 & 5.4 \\
\hline Grade 4 & 3.6 & 2.7 & 1.8 & 3.6 & 2.7 \\
\hline \multicolumn{6}{|l|}{ Hypogammaglobulinemiat† } \\
\hline Grade 3 & 0 & 2.7 & 2.7 & 0 & 1.8 \\
\hline
\end{tabular}

*Values are the percentage unless otherwise indicated. AE = adverse event; MedDRA = Medical Dictionary for Regulatory Activities.

† Placebo serious and severe infections: wound infection, viral infection, bilateral pneumonia, herpes zoster (severe only), pneumonia (severe only), and furuncle (graded serious and severe).

‡ Belimumab $1.0 \mathrm{mg} / \mathrm{kg}$ serious and severe infections: acute bronchitis, cellulitis, urinary tract infection (severe only), infected skin ulcer (severe only), viral gastroenteritis (graded serious and severe), lobar pneumonia (graded serious and severe), pneumonia (graded serious and severe; 2 patients), septic arthritis-streptobacillus (graded serious and severe) and cellulitis (2 events for the same patient), and bacterial pneumonia (graded serious and severe).

§ Belimumab $4.0 \mathrm{mg} / \mathrm{kg}$ serious and severe infections: streptococcal bacteremia, acute pyelonephritis, viral infection, upper respiratory tract infection (severe only; 2 patients), cellulitis (graded serious and severe) and pneumonia (graded serious and severe; 2 events for the same patient), acute bronchitis (graded serious and severe) and urinary tract infection (2 events for the same patient), and West Nile viral infection (graded serious and severe).

II Belimumab $10.0 \mathrm{mg} / \mathrm{kg}$ serious and severe infections: herpes zoster, clostridium colitis, upper respiratory tract infection (severe only), postoperative infection (severe only), anal infection (graded serious and severe), and sepsis (graded serious and severe).

\# Includes life-threatening events.

** A total of $11.9 \%$ of belimumab-treated patients and $8.9 \%$ of placebo-treated patients were receiving warfarin; 18 patients with grade $3 / 4$ prothrombin time were not receiving warfarin, and only 2 of these patients ( 1 placebo and 1 belimumab $10 \mathrm{mg} / \mathrm{kg}$ ) had $>1$ prolonged prothrombin time value during the study.

t† Grade $3=<400 \mathrm{mg} / \mathrm{dl}$ of IgG. Four of the 6 patients had IgG levels below the lower limit of normal at baseline, and only 1 patient had at least a grade 2 shift from grade 0 to 3 . Overall, the percentage of patients who had immunoglobulin levels below the lower limit of normal at baseline compared with week 52 were as follows: IgG: $5.3-6.4 \%$ placebo vs. 5.7-7.2\% belimumab (all active); IgA: 7.1-7.4\% placebo vs. 5.7-8.3\% belimumab (all active); and IgM: $17.7-19.4 \%$ placebo vs. $14.7-31.4 \%$ belimumab (all active). 
(72.6\% versus $57.8 \% ; P=0.0027)$, lower C3 and C4 levels $(P<0.0001)$, higher immunoglobulin levels (IgG, IgA, and IgE; all $P \leq 0.001)$, lower baseline CD19+ and CD20+ B cell counts $(P \leq 0.01)$, and more often detectable $(\geq 0.350$ ng/ml) BLyS levels (51\% versus 24\%; $P<0.0001$ ) (29).

Serologically active patients treated with belimumab had significantly greater reductions in SELENA-SLEDAI scores from baseline to week $52(-28.8 \%$ in the combined belimumab group versus $-14.2 \%$ in the placebo group; $P$ $=0.0435$ ) and using modified SELENA-SLEDAI scoring that excluded contributions of anti-dsDNA and low complement levels (Table 2). In addition, belimumab treatment resulted in improvements in both the PGA $(-32.7 \%$ in the combined belimumab group versus $-10.7 \%$ in the placebo group; $P=0.0011$ ) and the SF-36 PCS (3.0-point increase in the combined belimumab group versus 1.2point increase in the placebo group; $P=0.041$ ). There was no significant effect seen in the BILAG composite score (data not shown). However, there were fewer new BILAG A or B flares in the combined belimumab group than in the placebo group (29.4\% versus $39.5 \% ; P=0.0871$ ) (Table 2 ). An analysis of treatment effects on PGA revealed that $63.8 \%$ of belimumab-treated versus $46.5 \%$ of placebotreated serologically active patients $(P=0.0054)$ had a $>0.3$-point improvement in PGA.

Overall, there were no statistically significant differences in biomarker responses between serologically active patients and all patients (data not shown), or between serologically active patients and seronegative patients (data not shown). In addition, in serologically active patients, there were no significant differences across belimumab dosing groups or between treatment and placebo groups in safety profile (data not shown).

\section{DISCUSSION}

In this phase II study, belimumab treatment combined with SOC therapy in SLE patients with active disease did not result in significant improvements compared with placebo as assessed by the coprimary end points of SELENASLEDAI score reduction at week 24 or reduction in the time to first SLE flare over 52 weeks. Nevertheless, this trial provided evidence that belimumab was well tolerated and improved many secondary disease activity measures (SLE flares, PGA, SELENA-SLEDAI score, and SF-36 PCS) when added to SOC in a large $(71.5 \%)$ subpopulation of serologically active patients. It generated a clinically meaningful hypothesis that provides the basis for the design of phase III confirmatory studies. This phase II study provided 4 valuable insights into the pharmacodynamics of belimumab, SLE disease activity, and trial design.

First, significant early reductions in selected B cells initially observed 4 to 8 weeks after belimumab treatment and early improvement in PGA observed at 4 weeks after belimumab treatment appear to require time to translate into clinically important benefits as measured by the SELENA-SLEDAI or SFI. Support for this assertion lies in the analysis of time to first SLE flare after 24 weeks, which showed significant lengthening from 108 days in the placebo group to 154 days in the belimumab groups.
Second, the presumption of an annual flare rate of $65 \%$ to $70 \%$ was too low. Eighty-seven percent of patients in this study had a mild/moderate or severe flare by week 52 , which was greater than the annual frequency (65\%) reported by the SELENA-SLEDAI group (21) employing the same flare instrument. Using new BILAG A or B domain scores as a definition of flare (30), it was observed that $69 \%$ of patients had a flare in 1 year. Additionally, in 3 trials evaluating the effects of oral contraceptives (OCs) (20), contraceptive methods (CMs) (31), or hormone replacement therapy (HRT) (32) on SLE disease activity, the 1-year SFI flare rates were 76\% (OC), 69\% (OC placebo), $67 \%$ (CM-OC), 74\% (CM-progestin or intrauterine device), $64 \%$ (HRT), and 51\% (HRT placebo). The high early flare rate in our study made it difficult to detect an effect, and it was probably related to greater disease activity (baseline SELENA-SLEDAI score 9.6) in our study population compared with those reported in recent long-term studies in which baseline SELENA-SLEDAI scores were 3.2 (20), 5.8 (31), 2.5 (32), and 3.3 (16).

Third, permitting unlimited changes in prednisone and immunosuppressive medications during the trial could have confounded SLE disease activity assessments. Additional therapy, especially when given within 8 weeks of week 52, could have affected study end points. Prednisone use was lower in the belimumab groups, as evidenced by greater percentages of patients having reduced prednisone by $\geq 50 \%$ or to $<7.5 \mathrm{mg} /$ day, and fewer patients required an increase to $>7.5 \mathrm{mg} /$ day than those in the placebo group. Less prednisone use among belimumab-treated patients could have blunted the detection of a difference from placebo-treated groups.

Fourth, serologically active patients were far more appropriate for belimumab B cell-targeted therapy than seronegative patients. Although $98 \%$ of patients had verified reports of previously positive ANA tests or other SLE autoantibodies, only $71.3 \%$ of patients had an ANA titer of $\geq 1: 80$ at baseline and $50 \%$ were anti-dsDNA antibody positive. Although some of this discrepancy could be attributed to a lack of uniformity between autoantibody testing laboratories, the finding that a significant improvement in the SELENA-SLEDAI score at week 52 with belimumab was associated with serologically active patients at screening and baseline strongly suggests that this was a more clinically active population. BLyS levels above the limit of quantitation at baseline were detected in twice as many serologically active (51\%) as seronegative $(24 \%)$ patients. Serologically active patients were significantly more responsive to belimumab, particularly in PGA and SF-36 PCS responses. Therefore, a subset of seronegative patients making up $28 \%$ of the original cohort could have confounded the assessment of belimumab efficacy.

Depletion (63-71\%) of CD20+ subsets of naive, activated, and plasmacytoid B cells after 1 year of treatment confirmed that belimumab was biologically active and also supports the role of BLyS as an essential B cell growth and survival factor. A more rapid reduction of $B$ cell subsets occurred in the first 6 months than in the second 6 months. Peripheral memory B cells doubled in number after 1 month of belimumab treatment, but returned to baseline levels by 1 year. The initial increase of memory B cells 
may be secondary to a release from disrupted lymphoid germinal centers, as seen in cynomolgus monkeys (18), or caused by inhibition of memory B cell return to germinal centers (33) or promotion of differentiation of naive B cells to memory B cells. Peripheral blood plasma cells were not reduced following a year of belimumab therapy. Patients receiving belimumab had decreases in a plasma cell subset that has been correlated with SLE activity (27), whereas there was an increase in placebo patients. Plasma cell survival has been shown to be more dependent on BCMA expression because there is less BAFF-R/BR-3 expression on plasma cells than on CD20+ B cells (34-36), and plasmablasts appear more dependent on APRIL for bone marrow survival (37). One year of belimumab therapy led to a $29 \%$ reduction in IgG anti-dsDNA antibodies compared with a $10 \%$ reduction in IgG, suggesting a selective effect on autoantibody-producing cells thought to be short-lived plasmablasts or plasmacytoid B cells $(27,38)$.

Belimumab in combination with SOC was well tolerated. The incidence of AEs, serious or severe AEs, reasons for discontinuation, and laboratory abnormalities were similar across the 3 doses of belimumab and the placebo group. There was no dose relationship for infection rates or serious infections for patients receiving belimumab, and no specific type of infection was prominent in any of the 4 treatment groups. The preservation of long-lived plasma cells and memory B cells, and only a modest reduction in IgG likely contributed to the similar infection rates in the belimumab and placebo groups. In murine SLE, animals given anti-BLyS antibody therapy had similar alterations in B cells, and there were no significant effects on primary and secondary immune responses (35).

In summary, developing new therapies for a heterogeneous disease such as SLE remains challenging (39). Use of the SELENA-SLEDAI and BILAG disease activity scales in this large randomized controlled trial identified limitations and strengths of these tools, and suggested that using the same scales to show improvement and worsening could be problematic. Therefore, to demonstrate the effectiveness of belimumab while complying with regulatory requirements and with the Food and Drug Administration draft guidance document on the development of therapies for SLE, a novel combined end point based on the data from this phase II study was developed (40). The results of this trial provided valuable information with which to design 2 large phase III SLE studies evaluating the effects of 2 doses of belimumab in serologically active SLE patients.

\section{AUTHOR CONTRIBUTIONS}

All authors were involved in drafting the article or revising it critically for important intellectual content, and all authors approved the final version to be submitted for publication. Dr. Wallace had full access to all of the data in the study and takes responsibility for the integrity of the data and the accuracy of the data analysis.

Study conception and design. Wallace, Stohl, Furie, McKay, Petri, Fernandez, Chevrier, Zhong, Freimuth.

Acquisition of data. Wallace, Stohl, Furie, Lisse, McKay, Merrill, Petri, Ginzler, Chatham, McCune, Fernandez, Chevrier, Zhong, Freimuth.
Analysis and interpretation of data. Wallace, Stohl, Furie, Merrill, Petri, Ginzler, McCune, Chevrier, Zhong, Freimuth.

\section{REFERENCES}

1. Moore PA, Belvedere O, Orr A, Pieri K, LaFleur DW, Feng P, et al. BLyS: member of the tumor necrosis factor family and B lymphocyte stimulator. Science 1999;285:260-3.

2. Gross JA, Johnston J, Mudri S, Enselman R, Dillon SR, Madden $\mathrm{K}$, et al. TACI and BCMA are receptors for a TNF homologue implicated in B-cell autoimmune disease. Nature 2000; 404:995-9.

3. Xia XZ, Treanor J, Senaldi G, Khare SD, Boone T, Kelley M, et al. TACI is a TRAF-interacting receptor for TALL-1, a tumor necrosis factor family member involved in B cell regulation. J Exp Med 2000;192:137-43.

4. Yan M, Brady JR, Chan B, Lee WP, Hsu B, Harless S, et al. Identification of a novel receptor for B lymphocyte stimulator that is mutated in a mouse strain with severe B cell deficiency. Curr Biol 2001;11:1547-52.

5. Do RK, Hatada E, Lee H, Tourigny MR, Hilbert D, Chen-Kiang S. Attenuation of apoptosis underlies B lymphocyte stimulator enhancement of humoral immune response. J Exp Med 2000;192:953-64.

6. Gross JA, Dillon SR, Mudri S, Johnston J, Littau A, Roque R, et al. TACI-Ig neutralizes molecules critical for B cell development and autoimmune disease: impaired B cell maturation in mice lacking BLyS. Immunity 2001;15:289-302.

7. Khare SD, Sarosi I, Xia XZ, McCabe S, Miner K, Solovyev I, et al. Severe B cell hyperplasia and autoimmune disease in TALL-1 transgenic mice. Proc Natl Acad Sci U S A 2000;97: 3370-5.

8. Mackay F, Woodcock SA, Lawton P, Ambrose C, Baetscher M, Schneider P, et al. Mice transgenic for BAFF develop lymphocytic disorders along with autoimmune manifestations. J Exp Med 1999;190:1697-710.

9. Jacob CO, Pricop L, Putterman C, Koss MN, Liu Y, Kollaros M, et al. Paucity of clinical disease despite serological autoimmunity and kidney pathology in lupus-prone New Zealand mixed 2328 mice deficient in BAFF. J Immunol 2006;177: 2671-80.

10. Kayagaki N, Yan M, Seshasayee D, Wang H, Lee W, French $\mathrm{DM}$, et al. BAFF/BLyS receptor 3 binds the B cell survival factor BAFF ligand through a discrete surface loop and promotes processing of NF-kB2. Immunity 2002;17:515-24.

11. Cheema GS, Roschke V, Hilbert DM, Stohl W. Elevated serum B lymphocyte stimulator levels in patients with systemic immune-based rheumatic diseases. Arthritis Rheum 2001;44: 1313-9.

12. Groom J, Kalled SL, Cutler AH, Olson C, Woodcock SA, Schneider P, et al. Association of BAFF/BLyS overexpression and altered B cell differentiation with Sjögren's syndrome. J Clin Invest 2002;109:59-68.

13. Mariette X, Roux S, Zhang J, Bengoufa D, Lavie F, Zhou T, et al. The level of BLyS (BAFF) correlates with the titre of autoantibodies in human Sjögren's syndrome. Ann Rheum Dis 2003;62:168-71.

14. Zhang J, Roschke V, Baker KP, Wang Z, Alarcon GS, Fessler BJ, et al. Cutting edge: a role for B lymphocyte stimulator in systemic lupus erythematosus. J Immunol 2001;166:6-10.

15. Collins CE, Gavin AL, Migone TS, Hilbert DM, Nemazee D, Stohl W. B lymphocyte stimulator (BLyS) isoforms in systemic lupus erythematosus: disease activity correlates better with blood leukocyte BLyS mRNA levels than with plasma BLyS protein levels. Arthritis Res Ther 2006;8:R6.

16. Petri M, Stohl W, Chatham W, McCune WJ, Chevrier M, Ryel J, et al. Association of plasma B lymphocyte stimulator levels and disease activity in systemic lupus erythematosus. Arthritis Rheum 2008;58:2453-9.

17. Baker KP, Edwards BM, Main SH, Choi GH, Wager RE, Halpern WG, et al. Generation and characterization of LymphoStat-B, a human monoclonal antibody that antagonizes the 
bioactivities of B lymphocyte stimulator. Arthritis Rheum 2003;48:3253-65.

18. Halpern WG, Lappin P, Zanardi T, Cai W, Corcoran M, Zhong J, et al. Chronic administration of belimumab, a BLyS antagonist, decreases tissue and peripheral blood B-lymphocyte populations in cynomolgus monkeys: pharmacokinetic, pharmacodynamic, and toxicologic effects. Toxicol Sci 2006;91: 586-99.

19. Furie R, Stohl W, Ginzler EM, Becker M, Mishra N, Chatham $\mathrm{W}$, et al. Biologic activity and safety of belimumab, a neutralizing anti-B-lymphocyte stimulator (BLyS) monoclonal antibody: a phase I trial in patients with systemic lupus erythematosus. Arthritis Res Ther 2008;10:R109.

20. Petri M, Kim MY, Kalunian KC, Grossman J, Hahn BH, Sammaritano LR, et al. Combined oral contraceptives in women with systemic lupus erythematosus. N Engl J Med 2005;353: 2550-8.

21. Petri M, Buyon J, Kim M. Classification and definition of major flares in SLE clinical trials. Lupus 1999;8:685-91.

22. Hay EM, Bacon PA, Gordon C, Isenberg DA, Maddison P, Snaith ML, et al. The BILAG index: a reliable and valid instrument for measuring clinical disease activity in systemic lupus erythematosus. Q J Med 1993;86:447-58.

23. Isenberg DA, Gordon C. From BILAG to BLIPS: disease activity assessment in lupus past, present and future. Lupus 2000; 9:651-4.

24. Ware JE Jr, Gandek B. Overview of the SF-36 health survey and the International Quality of Life Assessment (IQOLA) project. J Clin Epidemiol 1998;51:903-12.

25. Hochberg MC, for the Diagnostic and Therapeutic Criteria Committee of the American College of Rheumatology. Updating the American College of Rheumatology revised criteria for the classification of systemic lupus erythematosus [letter]. Arthritis Rheum 1997;40:1725.

26. Cambridge G, Leandro MJ, Teodorescu M, Manson J, Rahman A, Isenberg DA, et al. B cell depletion therapy in systemic lupus erythematosus: effect on autoantibody and antimicrobial antibody profiles. Arthritis Rheum 2006;54:3612-22.

27. Jacobi AM, Odendahl M, Reiter K, Bruns A, Burmester GR, Radbruch A, et al. Correlation between circulating CD27 $7^{\text {high }}$ plasma cells and disease activity in patients with systemic lupus erythematosus. Arthritis Rheum 2003;48:1332-42.

28. Strand V, Crawford B. Improvement in health-related quality of life in patients with SLE following sustained reductions in anti-dsDNA antibodies. Expert Rev Pharmacoeconomics Outcome Res 2005;5:317-26.
29. Petri M, Wallace DJ, Stohl W, McKay J, Stern S, Furie R, et al. SLE patients with active production of anti-nuclear autoantibodies (ANA) have distinct patterns of lupus activity and peripheral B-cell biomarkers compared to ANA negative patients [abstract]. Ann Rheum Dis 2006;65 Suppl 2:356.

30. Gordon C, Sutcliffe N, Skan J, Stoll T, Isenberg DA. Definition and treatment of lupus flares measured by the BILAG index. Rheumatology (Oxford) 2003;42:1372-9.

31. Sanchez-Guerrero J, Uribe AG, Jimenez-Santana L, MestanzaPeralta M, Lara-Reyes P, Seuc AH, et al. A trial of contraceptive methods in women with systemic lupus erythematosus. N Engl J Med 2005;353:2539-49.

32. Buyon JP, Petri MA, Kim MY, Kalunian KC, Grossman J, Hahn $\mathrm{BH}$, et al. The effect of combined estrogen and progesterone hormone replacement therapy on disease activity in systemic lupus erythematosus: a randomized trial. Ann Intern Med 2005;142:953-62.

33. Badr G, Borhis G, Lefevre EA, Chaoul N, Deshayes F, Dessirier $\mathrm{V}$, et al. BAFF enhances chemotaxis of primary human B cells: a particular synergy between BAFF and CXCL13 on memory B cells. Blood 2008;111:2744-54.

34. O'Connor BP, Raman VS, Erickson LD, Cook WJ, Weaver LK, Ahonen C, et al. BCMA is essential for the survival of longlived bone marrow plasma cells. J Exp Med 2004;199:91-8.

35. Scholz JL, Crowley JE, Tomayko MM, Steinel N, O’Neill PJ, Quinn WJ 3rd, et al. BLyS inhibition eliminates primary B cells but leaves natural and acquired humoral immunity intact. Proc Natl Acad Sci U S A 2008;105:15517-22.

36. Zhang X, Park CS, Yoon SO, Li L, Hsu YM, Ambrose C, et al. BAFF supports human B cell differentiation in the lymphoid follicles through distinct receptors. Int Immunol 2005;17: 779-88.

37. Belnoue E, Pihlgren M, McGaha TL, Tougne C, Rochat AF, Bossen C, et al. APRIL is critical for plasmablast survival in the bone marrow and poorly expressed by early-life bone marrow stromal cells. Blood 2008;111:2755-64.

38. Avery DT, Kalled SL, Ellyard JI, Ambrose C, Bixler SA, Thien $\mathrm{M}$, et al. BAFF selectively enhances the survival of plasmablasts generated from human memory B cells. J Clin Invest 2003;112:286-97.

39. Merrill JT, Erkan D, Buyon JP. Challenges in bringing the bench to bedside in drug development for SLE. Nat Rev Drug Discov 2004;3:1036-46.

40. Furie RA, Petri MA, Wallace DJ, Ginzler EM, Merrill JT, Stohl W, et al. Novel evidence-based systemic lupus erythematosus responder index. Arthritis Rheum 2009;61:1143-51. 